\title{
Somatotopy within the Internal Capsule Illustrated by Diffusion Tensor Tractography
}

\author{
Michel Golay ${ }^{a}$ Reto Meuli ${ }^{b} \quad$ Alexandre Croquelois ${ }^{a}$ \\ Departments of a Neuropsychology and Neurorehabilitation, and ${ }^{\mathrm{b}}$ Radiology, Centre Hospitalier Universitaire \\ Vaudois and University of Lausanne, Lausanne, Switzerland
}

A 65-year-old man, known for active cigarette smoking, suddenly developed, shortly after awakening, a left paresis of the face, arm and leg associated with hypoesthesia and hemineglect. CT perfusion and angiography scans revealed a right internal carotid artery occlusion (fig. 1a) with a large penumbra within the right middle cerebral artery (MCA) territory and a definitive infarct within the posterior limb of the internal capsule (fig. 1df). Rt-PA intravenous injection was initiated at $80 \mathrm{~min}$ from symptom onset. Clinical evolution was characterized by recovery of hypoesthesia, hemineglect and face and arm strength. An MRI obtained at day 34 after stroke onset confirmed the restricted right capsular infarct and revealed an almost complete rescue of the penumbra within the right MCA territory on $\mathrm{T}_{2}$-weighted images (fig. 1c). Diffusion tensor imaging demonstrated fiber discontinuation within the posteromedial part of the posterior limb of the right internal capsule, when fibers passing through the anterolateral part were relatively spared (fig. $1 g-\mathrm{j}$ ).

\author{
References $\quad 1$ Mukherjee P, Berman JI, Chung SW, Hess \\ CP, Henry RG: Diffusion tensor MR imaging \\ and fiber tractography: theoretic underpin- \\ nings. AJNR Am J Neuroradiol 2008;29: \\ 632-641. \\ 2 Kretschmann HJ: Localisation of the corti- \\ cospinal fibres in the internal capsule in \\ man. J Anat 1988;160:219-225.
}

Fig. 1. a CT angiography. Note the right internal carotid artery occlusion. b Native CT scan demonstrating early infarct signs within the internal capsule (white arrow). c $\mathrm{T}_{2}$-weighted MRI demonstrating a restricted right capsular infarct. c-e CT perfusion demonstrating a large penumbra within the right MCA territory, defined by a decrease in cerebral blood flow and a preserved cerebral blood volume (d-f, white arrowheads), and a definitive infarct within the posterior limb of the internal capsule, defined by a decrease in cerebral blood flow and a decreased cerebral blood volume (d-f, white arrows). Regions of interest defined within the posterior limb of the internal capsule on ADC maps ( $\mathbf{g}$ and $\mathbf{h}$ ) allowed to determine the fiber tracks [1] (i-j) and showed an almost complete interruption of posteromedial fibers (blue) corresponding to the lower limb representation [2] that was related to a residual crural monoparesis.

\section{KARGER}

Fax +41613061234 E-Mail karger@karger.ch www.karger.com (c) 2009 S. Karger AG, Basel

0014-3022/09/0624-0250\$26.00/0

Accessible online at:

www.karger.com/ene
Alexandre Croquelois, MD

Department of Neuropsychology and Neurorehabilitation

Centre Hospitalier Universitaire Vaudois (CHUV)

Avenue Pierre-Decker 5, CH-1011 Lausanne (Switzerland)

Tel. +41 21314 14 76, Fax +41 2131477 56, E-Mail alexandre.croquelois@chuv.ch 


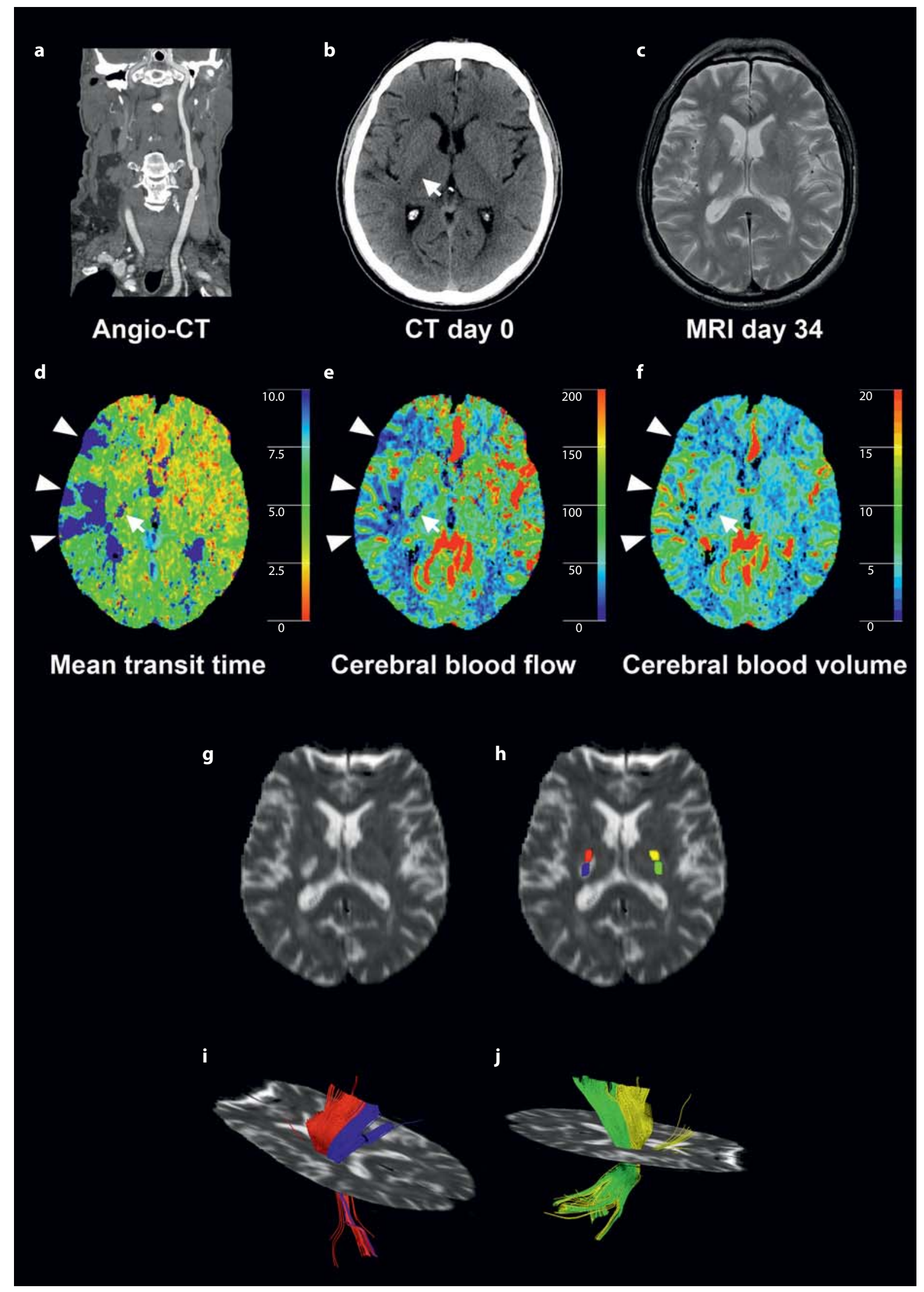

